\title{
PELATIHAN KETERAMPILAN DASAR MICROSOFT WORD KEPADA ANAK- ANAK YAYASAN PEDULI BANGSA BANTEN
}

\author{
1)Agustin Wahyuni, 2)Ayasya Zhafirah, 3)Buko Setiawan 4)Cindy Fathia Nurrul, \\ 5) Vannywati Dewi
}

\author{
1,2,3,4,5 Mahasiswa Prodi Sekretari D-III Universitas Pamulang \\ Agustinwahyuni248@gmail.com
}

\begin{abstract}
ABSTRAK
Di era globalisasi ini, banyak sekali pekerjaan yang dalam penyelesaiannya harus menggunakan komputer salah satunya dengan software Microsoft Office, seperti halnya dalam surat-menyurat, membuat proposal, membuat presentasi atau pelatihan, dan masih banyak lagi. Kemampuan tersebut harus dimilki semua individu agar tidak tertinggal dalam kemajuan teknologi. Menyadari pentingnya kemampuan penguasaan program Microsoft Office, penulis bersama-sama ingin memperkenalkan dasar-dasar program Microsoft Word kepada anak-anak di Yayasan Peduli Bangsa Banten dengan tujuan agar mereka tidak tertinggal terlalu jauh ketika nanti mendapatkan tugas sekolah yang berhubungan dengan Microsoft Word ini, apalagi kami menyadari bahwa sekolah daring yang saat ini sedang diterapkan membuat kegiatan belajar anak-anak tidak maksimal tanpa adanya pengawasan guru.
\end{abstract}

Kata Kunci: Globalisasi, Keterampilan, Microsoft Word

\begin{abstract}
In this era of globalization, there are so many jobs that have to be completed using a computer, one of which is with Microsoft Office software, such as in correspondence, making presentations or exercises, and much more. This ability must be owned by all individuals so as not to be left behind in technological progress. the importance of mastering Microsoft Office programs, the authors would like to introduce the basic Microsoft Word program to children at the Banten Peduli Bangsa Foundation with the aim of not being too far behind when they get school assignments related to Microsoft Word, moreover we realize that school The courage that is currently being implemented makes children's learning activities not optimal without the supervision of the teacher.
\end{abstract}

Keywords: Globalization, Skill, Microsoft Word 


\section{PENDAHULUAN}

Pengabdian Kepada Masyarakat (PKM) ini merupakan Kebijakan baru Mendikbud yang tertuang dalam (Kemendikbud, 2020) tentang 8 Indikator Kinerja Utama (IKU) yang menjadi landasan transformasi pendidikan tinggi di Indonesia. Dalam 8 IKU tersebut penilaiannya berdasar beberapa hal dan yang langsung berhubungan dengan mahasiswa adalah lulusan PT mendapatkan pekerjaan yang layak serta mahasiswa mendapatkan pengalaman di luar kampus. Secara umum, tujuannya adalah untuk mempersiapkan sumber daya manusia yang berorientasi ke masa depan dan ditempa dengan transformasi Pendidikan Tinggi sehingga menjadi lulusan yang unggul, kompetitif, adaptif, fleksibel, produktif, berdaya saing dengan karakter Pancasila, serta memandu mahasiswa menjadi pribadi yang (1) Tahu dan taat aturan; (2) Kreatif dan inovatif; (3) Objektif kooperatif dalam membangun keragaman intelektual.

Topik Pengabdian Kepada Masyarakat tidak dibatasi, namun diutamakan topik kekinian atau topik utama Sustainable Delovelopmens Goals (SDGs). Mahasiswa diajak menuju kampus merdeka merdeka belajar, mahasiswa belajar diluar kampus misal berinteraksi dengan masyarakat di luar kampus baik masyarakat pengusaha (orientasi profit) juga masyarakat non profit. Demikian pula mahasiswa dapat menumbuhkembangkan HOTS (Higher Order Thinking Skills), Creative Thinking dan Critical Thinking melalui implementasi filosofi Tri Dharma Perguruan Tinggi (Gambar 1) yaitu (1) Pendidikan dan pengajaran; (2) Penelitian dan pengembangan; (3) Pengabdian kepada masyarakat.

Pengabdian Kepada Masyarakatini merupakan salah satu agenda yang diwajibkan oleh Universitas Pamulang kepada seluruh mahasiswanya. Dengan berjalannya program ini, maka citra baik Universitas Pamulang bisa terbentuk di kalangan masyarakat sekitar Universitas Pamulang yang menjadi tempat mahasiswa melaksanakan program tersebut.

Pada saat ini kita memasuki era Society 5.0. Jika era Industry 4.0 berfokus pada produksi, Society 5.0 berupaya menempatkan manusia sebagai pusat inovasi (Nusantara, 2019). Yang artinya semua individu harus sudah melek teknologi untuk menunjang kegiatan sehari-hari yang tidak lepas dari penggunaan teknologi. Beberapa pekerjaan yang biasanya dilakukan secara konvensional, kini perlahan sudah bisa diselesaikan menggunakan teknologi. Terlebih lagi, sudah lebih dari satu tahun bumi yang kita tempati ini dilanda pandemic yang menghambat kegiatan di luar rumah. 
Pembatasan aktivitas di luar rumah dilakukan sebagai upaya untuk pencegahan tersebarnya COVID-19. Sehingga kegiatan yang biasanya dilakukan di luar rumah seperti sekolah dan bekerja, harus diganti metodenya agar bisa dilaksanakan tanpa pergi ke sekolah dan ke kantor menjadi sekolah daring dan work from home.

Semua orang awalnya pasti mengalami culture shock atau gegar budaya di era ini, terutama para pelajar sekolah dasar dan menengah pertama yang dituntut untuk memahami kecanggihan teknologi demi penunjang sekolah online. Menyadari bahwa masih banyak siswa sekolah dasar yang belum paham sama sekali teknologi, kami, kelompok mahasiswa D-3 Sekretari Universitas Pamulang yang beranggotakan lima orang, bermaksud untuk memperkenalkan dan memberikan pendampingan kepada anak-anak di Yayasan Peduli Bangsa Banten mengenai keterampilan dasar program Microsoft Word yang merupakan salah satu media untuk mengerjakan tugas-tugas sekolah mereka.

\section{METODE PELAKSANAAN}

Setelah kami melakukan survey ke Yayasan Peduli Bangsa Banten dan mengamati apa saja permasalahan yang tengah dirasakan oleh mayoritas adik-adik yang merupakan pelajar, maka kami sepakat untuk mengambil judul Pengabdian
Kepada Masyarakatsebagai berikut: "Pelatihan Keterampilan Dasar Microsoft Word kepada Anak-Anak di Yayasan Peduli Bangsa Banten.” Langkah berikut yang kami lakukan adalah dengan membuat proposal PKM yang kami ajukan kepada Ketua Program Studi Sekretari D-III. Proposal PKM yang diajukan kemudian akan di review oleh reviewer untuk kemudian disetujui oleh Ketua Program Studi D-III Sekretari. Setelah proposal PKM disetujui oleh Ketua Program Studi D-III Sekretari, maka kami melakukan berbagai persiapan terutama menyiapkan materi yang akan kami sampaikan pada kegiatan Pengabdian Kepada Masyarakat(PKM) untuk menumbuhkan pemahaman anak-anak di Yayasan terhadap penggunaan fitur-fitur Microsoft Word.

Berikut adalah tahapan-tahapan yang dilakukan oleh kelompok pelaksana Program Kreativitas Mahasiswa (PKM): (1)Tahap Persiapan: (a) Penentuan topik; (b) survey lokasi; (c) Pemantapan dan penentuan lokasi dan sasaran.

Penyusunan bahan atau materi mengenai dasar-dasar Microsoft Word, (3) Tahap Pelaksanaan Pelatihan. Pada tahap ini dijelaskan mengenai cara mengatasi kesukaran dalam belajar online dan mempraktikkan penggunaan fitur-fitur Microsoft Word kepada anak-anak. 


\section{HASIL DAN PEMBAHASAN}

Penulis membuat susunan acara kegiatan pada tanggal 11 April 2021 dimulai dengan pembukaan oleh ketua kelompok, dilanjutkan dengan sambutan dari Pengurus Yayasan Yaitu Bapak Jamaludin Dalam Sambutannya, Bapak Jamaludin Menyampaikan Visi Dan Misi Yayasan Peduli Bangsa Banten Yaitu

Beliau menyambut kedatangan mahasiswa dengan sukacita. Beliau menyampaikan bahwa kegiatan seperti inilah yang dibutuhkan oleh anak-anak di yayasan karena mayoritas dari mereka merupakan anak yatim dan dhuafa, sehingga kegiatan belajar mereka tidak bisa berjalan dengan efektif karena tidak adanya pengetahuan dan tidak adanya pendamping mereka dalam belajar. Sehingga kedatangan mahasiswa dapat memberikan insight dan konsultasi belajar sekaligus memberikan pelatihan yang benar-benar dibutuhkan oleh anak-anak di yayasan.

Inti dari kegiatan ini adalah anakanak dipersilakan untuk mengoperasikan Microsoft Word dengan laptop yang disediakan oleh mahasiswa. Beberapa dari mereka sudah paham mengenai penggunaan fitur-fitur yang ada pada Microsoft Word, dan beberapa juga hanya bisa mengetik tanpa mengetahui cara mengedit tulisan mereka dengan fitur yang sudah ada.
Setelah kurang lebih dua jam mempraktikkan pengoperasian Microsoft Word, kami menanyakan kesan yang mereka rasakan selama belajar bersama. Mereka mengatakan bahwa mereka senang dan bersyukur karena mendapatkan ilmu baru yang belum mereka dapatkan di Sekolah.

\section{KESIMPULAN DAN SARAN}

Berdasarkan hasil pelaporan dan pembahasan yang telah diuraikan penulis, maka kesimpulan yang dapat diambil adalah, anak-anak harus memiliki keterampilan menggunakan teknologi dalam upaya menghadapi era society 5.0 ini. Keterampilan itu bisa didapatkan apabila orang dewasa di sekitarnya pun terampil dan dengan sabar memperkenalkan satu persatu teknologi yang sudah menjadi makanan sehari-hari.

Penulis juga menyarankan agar adanya kebijakan yang baik dan konsisten dari Yayasan Peduli Bangsa Banten dalam memberikan pengetahuan serta pelatihan mengasah kreativitas melalui praktik pengoperasian software-software umum yang biasa digunakan dalam kehidupan pendidikan guna menghasilkan anak didik yang memiliki kualitas sumber daya manusia yang baik. 


\section{DAFTAR PUSTAKA}

Direktorat Jenderal Pembelajaran dan Kemahasiswaan. (2021). Program Kreativitas Mahasiswa - Pedoman Umum. Kewirausahaan (PKM-K), 3, 89-117.

Kemendikbud. (2020). Kepmendikbud Nomor 754/P/2020 Tentang Indikator Kinerja Utama Perguruan Tinggi Negeri dan Lembaga Layanan Pendidikan Tinggi di Lingkungan Kementerian pendidikan dan Kebudayaan Tahun 2020. 06 Agustus 2020.

Nusantara, T. (2019). Society 5.0 dan riset perguruan tinggi indonesia. 1-19.

http://rbqmetodealbana.blogspot.com Diakses tanggal 5 Oktober 2021.

http:pendis.kemenag.go.id. Diakses tanggal 1 Oktober 2021.

htp://eprints.stainkudus.ac.id/1834/5/5.\%2 0BAB\%20II.pdf. Diakses tanggal 1 Oktober 2021. 